\title{
Sustainability, Well-Being, and Happiness: A co-word Analysis
}

\author{
Angela Dettori, PhD \\ University of Cagliari \\ Department of Business and Economics \\ Viale Sant'Ignazio $78-09126$ \\ Cagliari (Italy) \\ Michela Floris, PhD \\ University of Cagliari \\ Department of Business and Economics \\ Viale Sant'Ignazio $78-09126$ \\ Cagliari (Italy)
}

\begin{abstract}
Sustainability has become increasingly essential due to its potential to address future challenges that will affect societies and economies. While a considerable amount of literatures has focused on environmental and economic factors, there is space for more studies on how sustainability can interact with well-being and happiness as new paradigms for individuals, communities, and organizations. With the aim of deeply analyzing this aspect, the paper, through a co-word analysis and a narrative literature review, explores the trend of academic papers and identifies a new field of research, extending previous studies introducing well-being and happiness as new drivers for sustainable behavior.
\end{abstract}

Keywords: sustainability, well-being, happiness

\section{Introduction}

The concept of sustainability comes from the simple principle that everything needed for survival and well-being depends, either directly or indirectly, on the environment in a broad sense (natural, social, political, cultural, economic, etc.)In this view, sustainability creates and sustains the conditions under which human beings can exist in harmony, by fulfilling the social, economic, and other requirements of present and future generations.

To achieve these conditions, sustainable individuals promote everyone's right and moderate access to natural, environmental, social, economic, political, and cultural resources (Ehrlich \&Ehrlich, 2009; Iwata, 2001). Moreover, sustainability-oriented people are cooperative and assist others in need (Pol, 2002), meaning they are "altruistically" motivated (Schultz, 2001). In this scenario, human behavior plays a paramount role in the emergence and support of environmental dynamics that requires a fundamental shift in people's behavior (Oskamp, 2000).

In light of these assumptions, inspired by the problematization perspective (Alvesson\& Sandberg, 2011), several questions need to be answered. For instance, what happens when sustainability is combined with well-being and happiness? Which perspectives on utility and connection with sustainability do they offer? To what extent do they represent a boundary topic? Is it the foundation of a new paradigm?

With the aim of finding interesting and stimulating answers to these and other questions and following the increasing prominence of sustainability, well-being, and happiness in recent academic debates, this paper challenges the various aspects of these concepts and takes into account synergies among them, through a co-word analysis and a narrative literature review.

Findings shed light on new perspectives within the sustainability research stream and are inspirational for practitioners. Finally, further researches are clearly shown to suggest new insights.

\section{Literature Background}

Sustainable development is defined as the "development which meets the needs of the present without compromising the ability of future generations to meet their own needs" (WCED, 1987). In its broadest sense, this normative abstraction has been widely accepted and endorsed by thousands of governmental, corporate, and other organizations worldwide (Gladwin, Krause,\& Kennelly, 1995). 
Today, sustainable development and sustainability jointly involve three different pillars: environmental, economic, and social. These dimensions are the basic elements of sustainability and sustainable development (Basiago, 1999; Munier, 2005; Hacking \&Guthrie, 2008). Generally, environmental sustainability can be described as environmental protection (Munier, 2005), and economic sustainability can be defined as economic growth and economic progress, although, as Munier asserts, "Economic growth does not necessarily mean a better living (...)" (Munier, 2005).Social sustainability is often related to problems such as poverty, social exclusion, unemployment, and inequalities, involving the like not only for present but also future generations (Partridge, 2005; Ekins, Dresner, \& Dahlstrom, 2008). Social sustainability, on a general or basic level, can also be seen as "a system of social organization that alleviates poverty, but in a more fundamental sense, however, social sustainability establishes the nexus between social conditions (such as poverty) and environmental decay." (Basiago, 1999).

Meanwhile, Sen (2009) considers the capabilities of human beings to be the basic components for a truly endogenous sustainable socio-economic development. If it is true that human beings are central in sustainable development, then similarly this development may be achieved only if human beings become a component of the environment-economysociety combination. This awareness has stimulated increasing studies, focused on well-being and happiness (Fukuda, Murakami, Noda, \& Oki, 2016; Barrington-Leigh, 2016).

In line with this view, several scholars (Dasgupta, 2004; Diaz, Fargione, Stuart Chapin, \& Tilman, 2006) have recently defined sustainability as a state of well-being and a deep-rooted belief that human beings can live in harmonious coexistence with the natural world. In addition, other scholars (Andersson, Nässén, Larsson, \& Holmberg, 2014) have defined sustainability with reference to well-being focusing on the basic requirements for good health, (cultural) identity, personal security, and freedom of choice.

The proliferation of studies within this field of research has generated the formation of two relatively distinct yet overlapping perspectives and paradigms for empirical research on well-being that revolve around two distinct philosophies. The first of these can be broadly labeled as hedonism (Kahneman, 1999), which reflects the view that well-being consists of pleasure or happiness. The second view, both as ancient and as current as the hedonic view, is that well-being consists of more than just happiness. The two traditions, hedonism and hedonic, are based on separate views of human nature and of what constitutes a just society. Accordingly, they ask different questions concerning how developmental and social processes relate to well-being, and they implicitly or explicitly prescribe different approaches.

As noted from this brief literature background, well-being and happiness appear interrelated and sometimes interchangeable with the expressions "quality of life" (Lyubomirsky \& Lepper, 1999; Veenhoven, 2007; Veenhoven, 2008; Alkire, 2015), "subjective well-being" (Levett, 2010), "life satisfaction," and "experiences" (Bekhet, Zauszniewski,\& Nakhla, 2008).

Abdel-Khalek (2005) states that happiness is the ultimate aim of human beings and that every human being wants and seeks happiness and satisfaction. Each human being has a different meaning of happiness, with various ways and means to achieve it. Therefore, human happiness cannot be guaranteed because human beings make their own choices and happiness differs from person to person. Some scholars (Bekhet, Zauszniewski, \& Nakhla, 2008; Alkire, 2015) conceptualize happiness as a positive inner experience, the highest good, the ultimate motivator for all human behaviors, and the degree to which an individual judges the overall quality of his or her life as a whole. On the basis of happiness, Tashi (2004) argues that this state of mind must be cultivated and nurtured through constant effort in understanding the causes and conditions that lead to happiness.

\section{Method}

To explore how the concepts of sustainability, well-being, and happiness have been jointly analyzed from academics, a bibliometric analysis, specifically the co-word analysis using SciMat (Cobo, Lòpez-Herrera, Herrera,\& HerreraViedma, 2012b) was conducted. Thisaims to highlight the intellectual structure of one field (Wu,Xie, Dai, \& Li, 2016; Khasseh, Soheili, Moghaddam, \& Chelak, 2017). It explores the relationship between words in the documents and the frequency of word occurrence is supposed to reveal and reflect the association, origin, and evolution of the underlying themes (Cobo, Lòpez-Herrera, Herrera,\& Herrera-Viedma, 2012a).

Subsequently, a narrative literature review was performed (Green, Johnson,\& Adams, 2001; Hammersley, 2001), synthesizing the findings on the concepts retrieved from the papers downloaded from the Scopus database to conduct the bibliometric analysis and in this way making a valuable contribution to the literature. To carry out the analysis, Scopus was chosen as the source to retrieve papers because it is the largest citation database of peer-reviewed literature including scientific journals, books, and conference proceedings. The considered time span is 1999-2017. 


\subsection{Research setting}

Based on the bibliometric principle that the most important knowledge on a topic is concentrated in only a small proportion of leading journals, citation data were retrieved from the Scopus database to conduct the searches and gather publication data. In the research, the following choice criteria were adopted:

1. Only articles with the author keywords combinations of "sustainability-well-being-happiness," "sustainability-wellbeing," and "sustainability-happiness" were considered.

2. Only articles were evaluated.

3. Only manuscripts written in English were selected.

4. The time limit was defined as 1999-2017.

\section{Findings}

The combination of author keywords entered in the Scopus database finds a total of 102 articles published between 1999 and 2017 that jointly analyze the themes of sustainability, well-being, and happiness. The interest about the topic is relatively new, in fact, in the last six years (2012-2017), the number of articles is exponentially increased (n. 63), while only eight papers appear from 1999 to 2005 and 31 from 2006 to 2011. This situation underlines the growing amount of attention that scholars are devoting to the topics in their researches. Figure 1 precisely shows the distribution of the published papers during the observed period.

\section{Figure 1-The Year-Wise distribution of the publication sample}

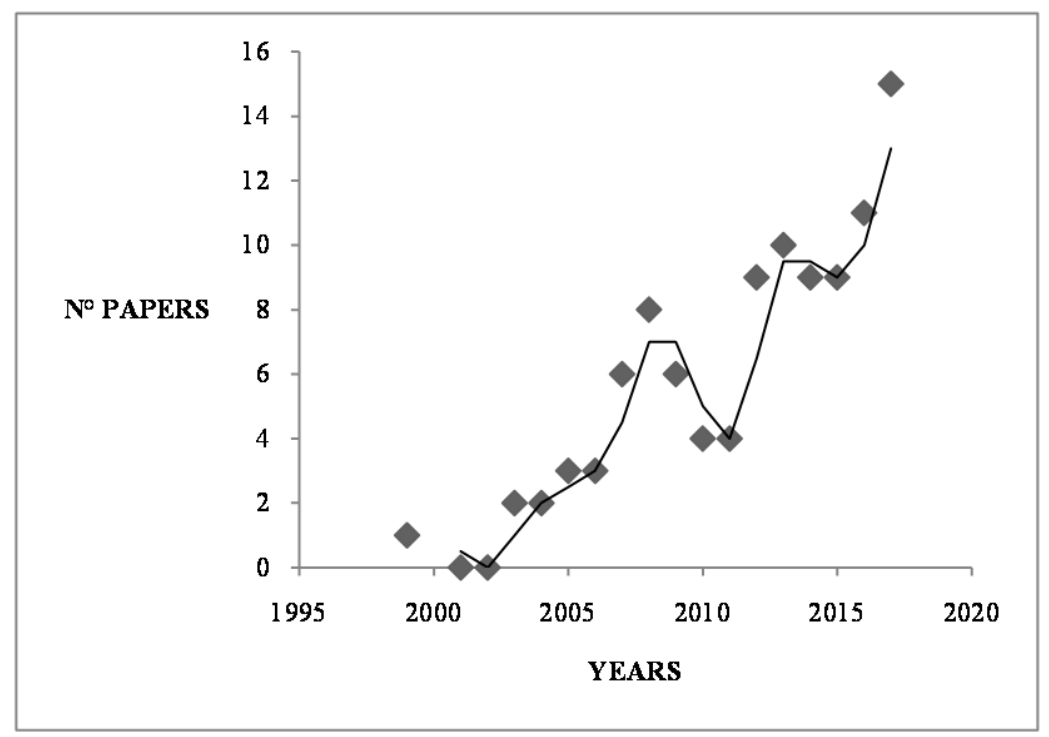

Source - Author's elaboration

The journals in which the selected articles were published are "Environment Journal" and "Psychology Journal." This is due to the psychological theories and empirical evidence which show solutions to socio-ecological problems to be found in human nature and its psychological predispositions, such as personal reasons, world views, future perspectives, environmental emotions, altruistic tendencies, and behavioral capacities, among other psychological predispositions that could allow for the adoption of sustainable lifestyles (Basiago, 1999; Bekhet, Zauszniewski,\& Nakhla, 2008; Levett, 2010; O'Brien, 2012; 2013). In addition, the reading of the 102 selected papers shows that 52\% of papers develop behavioral solutions and highlight the impact of sustainable behavior on human well-being (Buunk\& Schaufeli, 1999; Cacioppo, Gardner,\& Berntson, 1999; Bechtel \&Corral-Verdugo, 2010).

To analyze the predominant topics, indicated as keywords, all selected articles were downloaded on SciMat (Cobo, Lòpez-Herrera, Herrera, \& Herrera-Viedma, 2012b), which, through a guided procedure, allows for conduction of a coword analysis that verifies the most frequently noted words for the defined time span. SciMat enabled us to divide the period into sub-periods. However, because of the small number of papers analyzed, and the largest number of publications only appeared in recent years, it would be meaningless to perform an analysis with several sub-periods. 
In performing the narrative literature review (Green, Johnson, and Adams, 2006; Hammersley, 2001) the body of literature is summarized and conclusions are drawn on the investigated topic, providing a comprehensive background for understanding the current knowledge on sustainability and highlighting the relationships to new core topics, such as well-being and happiness.

As a result of this analysis, several interesting aspects are resulted, in particular for what concerns the role that psychological aspects and features play in sustainability, well-being and happiness jointly considered(see Figure 2). Moreover, these aspects are connected by the pillars of sustainable lifestyles (Basiago, 1999) and states of satisfaction (Bekhet, Zauszniewski,\& Nakhla, 2008) that lead to psychological well-being (Levett, 2010; O'Brien, 2012;2013; Kjell, 2011; Barrington,2016), referring to how people experience the quality of life (Veenhoven, 2007; Rojas, 2011), including emotional reactions (Iwata, 2001; Jacob, Brinkerhoff and Jovic, 2009) and cognitive judgments (Cacioppo, Gardner,\& Berntson, 1999).

Figure 1 - The keyword analysis

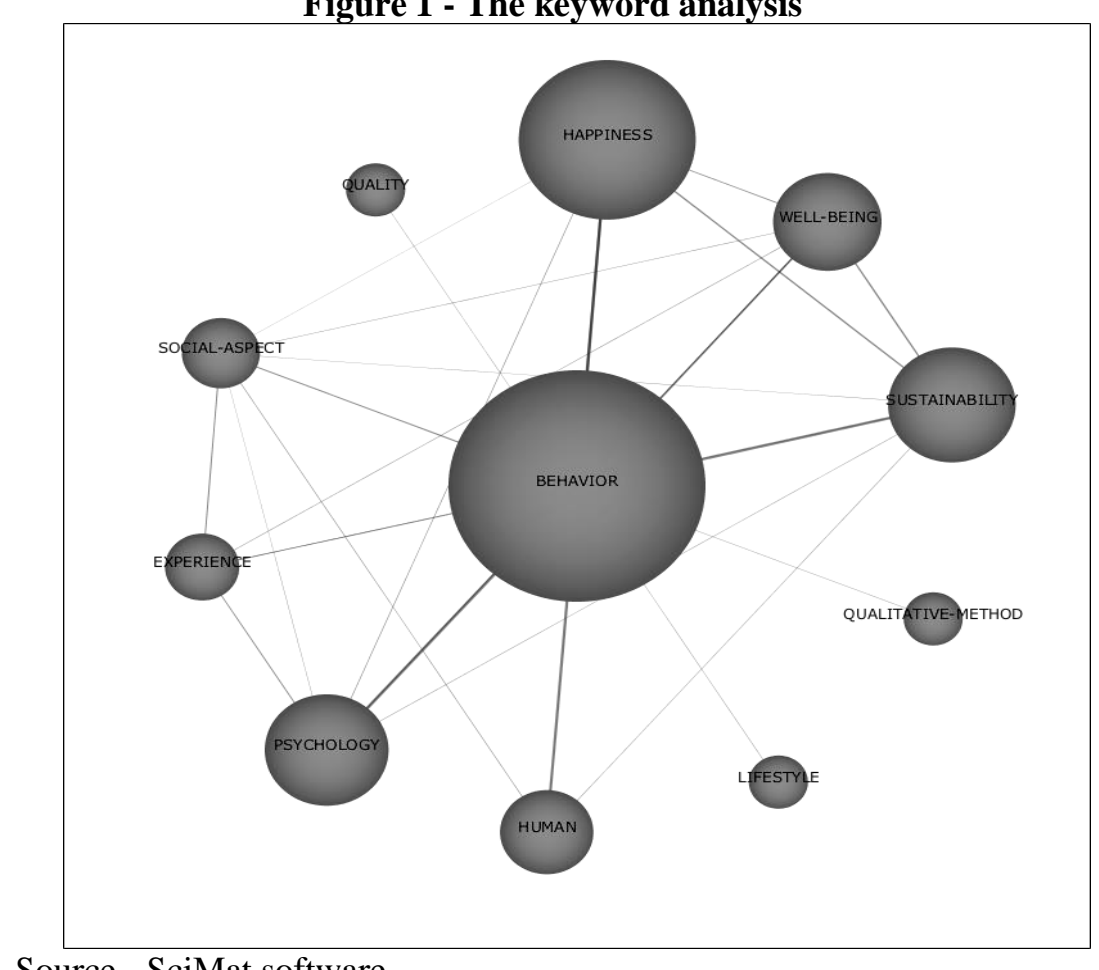

Source - SciMat software

Several studies (Oskamp, 2000; Vlek \& Steg, 2007; Robertson \&Cooper, 2009) provide psychological theories to explain the link between these issues. Indeed," qualitative approaches" to the study of these relationships emerge as keywords. In detail, these articles adopt case studies, conceptual and theoretical papers, and survey-based studies as their methodologies, but approximately $40 \%$ of the papers analyzed do not have any empirical component and use a theoretical and conceptual approach. This finding is not surprising for an unexplored field that is still attempting to lay down its foundations and define its intellectual boundaries.

In addition, social well-being, which comprises human happiness, quality of life, and aspects of environmental wellbeing, is an important factor that influences human behavior, and it is worth acknowledging that the ethical issue of how individuals may live a better or happier life has been widely discussed in the scientific literature (Basiago, 1999; Buunk \& Schaufeli, 1999).

Another interesting finding refers to the lack of studies that linking sustainability, well-being and happiness within the firm's field. In other words, the context of entrepreneurship and business is under-researched as underlined by the evidence that the keywords "enterprise, or firm, or company" do not emerge in the analysis. This does not mean that these concepts are not analyzed within the articles, but these are not present as the most commonly cited keywords. Only three contributions (Sneddon, Howarth, \& Norgaard, 2006; Robertson and Cooper, 2009; 2010; Oswald, Proto and Sgroi, 2014; Di Fabio, 2017) focus on the connection between sustainability, well-being and happiness within companies. These papers mainly consider these factors as a source of competitive advantage, stressing that a comfortable working climate and sustainable and responsible behaviors involve a state of well-being for firms and for employees. 


\section{Discussion}

The narrative review carried out has allowed understanding the trend and the future directions to address the topic. With the awareness of simplifying the complexity of the analyzed topic, the selected papers were grouped to identify common themes within the groups and differences among the groups. Following, the diverse groups are described, and a series of propositions emerge.

\subsection{Psychological issues}

The findings show an increasing interest from scholars and practitioners toward the topic, especially recently, when additional and new indicators have been proposed to evaluate the consequence of sustainability. These indicators mainly focus on psychological aspects that possess an intrinsically intangible essence and tend to come up the side the well-known environmental, social, and economic dimensions of sustainability. In other words, feelings as satisfaction, personal well-being, intrinsic motivation, and happiness (Kaiser, 1998; Iwata, 2001; Kasser, 2009, Rojas, 2011; Cloutier, Karner, Breetz, Briggs, \& Carlson, 2017) play a fundamental role in developing sustainability and promoting sustainable development.

Some studies have found the relevance of the concept of "justice," in terms of impartial treatment and compensation. In fact, individuals who perceive equality in their life and work context, experience a greater subjective well-being, although coincidentally, than individuals that perceive inequity experience negative feelings and frustration (Vlek \& Steg, 2007; Napier \&Jost, 2008). In line with this vein, studies underscore that altruistic individuals tend to be happier than egoistic individuals and that altruism allows people to experience happiness in their close relationships with others and feel good in the long term (Buunk \& Schaufeli, 1999; Bechtel \& Corral-Verdugo, 2010). As a tenet of sustainable lifestyles, frugality precipitates the states of satisfaction that lead not only to psychological well-being (Brown \& Kasser, 2005) but also to the satisfaction and intrinsic motivation that allow the maintenance of lighter levels of consumption (De Young, 1996; Iwata, 2001, Oswald, Proto, \& Sgroi, 2014; Di Fabio, 2017). Something similar occurs when such behaviors are aimed at preserving the physical environment. Individuals that practice eco-friendly behaviors are happier than individuals that are not considerate of green aspects (Brown \&Kasser, 2005; Turcotte, 2006; O'Brien, 2013; Barrington, 2016). In this scenario, happiness represents the contemporary antecedent of pro-environmental behavior (Cloutier et al., 2017) and a consequence of sustainable practices (Kasser, 2009) converging to achieve general well-being (Helne \& Hirvilammi, 2015).

In recent years, due to the escalating interest in happiness, several studies have aimed to lead people and organizations to find the "good life," achievable whether and when sustainability is partnered with well-being and happiness, creating what scholars label as "sustainable happiness" (O'Brien, 2008; 2013), that is "the pursuit of happiness that does not exploit other people, the environment or future generations" (O’Brien, 2008).

O'Brien (2005) develops the concept of sustainable happiness to draw attention to both positive and negative consequences of how individuals, communities, and nations pursue happiness. In a globalized world, policies and behaviors have effects on places and peoples around the world. Some impacts are immediate and short-term, while others have enduring effects, especially when being sustainable means being happy in the long term(O'Brien, 2012), or the awareness of mutual interdependence is emphasized in a transgenerational view, or when scholars underline the relevance that happiness studies play within the concept of sustainability (Kasser, 2009).

Recently, a scholar stated that "happiness should be an aim of education, and a good education that should contribute significantly to personal and collective happiness" (Noddings, 2003). To ensure happiness and environmental sustainability, sustainable happiness should be an aim of education and a good education of many organizations should contribute significantly to happiness and well-being.

These assumptions suggest that:

Proposition 1.The more sustainability, well-being, and happiness are deeply rooted in psychological aspects, the more they possess the intrinsic ability for transforming and inspiring individuals, communities, nations, and firms' behaviors. Proposition 2. The more that scholars pay attention to the relationship among sustainability, well-being, and happiness, the more well-being and happiness can be seen as new intangible pillars of sustainability.

\subsection{Lifestyles and human behavior}

Recently, scholars have extended their research focusing on antecedents and consequences of happiness (Choi, 2016), especially for what concerns the role of happiness within the firm context, in order to stimulate employees to be more committed and involved (Lim, Yoo, \& Won, 2016). Happiness, in this sense, appears to generate positive effects on health. Empirical studies, in fact, show that happiness is positively related with longevity (Evans, 2006; Veenhoven, 2008) and sustainable behaviors. 
In other words, happy people are expected to engage in sustainable behaviors as a result of positive emotions, and this engagement leads to caring more about nature, the environment, and future generations (Tapia,Corral-Verdugo, FraijoSing, \& Durón-Ramos, 2013), because "positive emotions are among the dispositional antecedents that promote sustainable behavior. Happiness, one of the most positive emotions (...) seems to be also related to a decreased consumption of resources" (Corral-Verdugo,Tapia, García, Varela, Cuen, \& Barrón, 2012).

These effects of happiness on health are investigated from an increasing number of scholars, in order to frame an emerging body of knowledge focused on the impact that positive feelings have on sustainability and resource management. Individuals who engage in resource management may experience boosts in both affective and evaluative forms of happiness as the very result of their sustainable behaviors (Jacob, Brinkerhoff, \& Jovic, 2009).

Moreover, the literature provides some explanations of human beings who, by virtue of engaging in simpler lives, experience increased feelings of satisfaction and meaning (Brülde, 2007). The first evidence surfaced in the beginning of the 1970s, when researchers conducted a survey among the first voluntary simplifiers, that is, people who consume less, spend less, reduce their ecological footprint, and are more community oriented (Elgin \&Mitchell, 1977). The testimonies of these early simplifiers show that they chose simplicity because it satisfies their psychological needs, allowing them to feel more autonomous, competent, and socially connected.

Another study conducted in 14 Chinese cities shows that individuals who display sustainable motivations and patterns of consumption directed at reducing waste and saving energy score higher on life satisfaction than individuals who are mildly or not engaged in green behaviors (Xiao \& Li, 2011). In addition, sustainable behaviors generally provide psychological rewards, such as positive emotions or higher life satisfaction (Iwata, 2001).

However, why do people experience happiness by living in a more sustainable way? Some scholars claim that producing less waste has positive effects on both life and domain satisfaction (Gandelman, Piani, \& Ferre, 2012). A pioneering study on the small holding movement in Canada showed that individuals obtain high satisfaction from simple living (including low consumption and waste production) because it increases their feeling of self-reliance (Brinkerhoff \&Jeffrey, 1984).

Finally, a sense of pleasure and well-being is produced when people engage in activities that ensure the survival of the individual and the species, leading to a state of happiness for people (Grinde, 2002; 2004).

The discussed assumptions suggest the following proposition:

Proposition 3: The happier people are, the more they adopt sustainable behaviors.

Proposition 4: The more the lifestyle is essential, the more people experience happiness and well-being and contribute to sustainability.

\subsection{Culture and socialization of positive behaviors}

"People who are happy don't necessarily engage in environmentally friendly behavior automatically. I believe that it depends on how you have been socialized. You could be very happy, and you could still be not aware of your impact on other people and the natural environment, if you have been socialized that way. But I think that once people do make the connection, that their happiness and well-being is interconnected with other people, then it creates a paradigm shift. And that helps sustain the sustainable behavior" (O'Brien, 2012). This means that sustainability, well-being, and happiness are strongly associated when a new culture takes form. Whether happiness research offers evidence that sustainable behaviors depend on the fulfillment of basic psychological needs, it is more incisive when socialized with the others, in order to create a sort of new culture based on shared perspectives, beliefs, and behaviors. Individuals, in fact, need to feel secure, autonomous, socially related, and competent in their everyday lives and generally, they adopt specific behaviors that represent shared norms and visions. Therefore, the challenge is socializing positive behaviors to involve people in adopting the same positive behaviors without forcing them to do so. This implicitly promotes sustainable outcomes.

The mentioned assumptions suggest the following propositions:

Proposition 5.The more that people socialize positive behavior, the more that sustainability, well-being, and happiness create a new shared culture.

Proposition 6. The more that culture is spread and shared among people, the more people become used to adopt positive behaviors.

The underlined propositions can be synthesized in the following interpretive model (Fig. 3): 
Figure 3 - The interpretive model

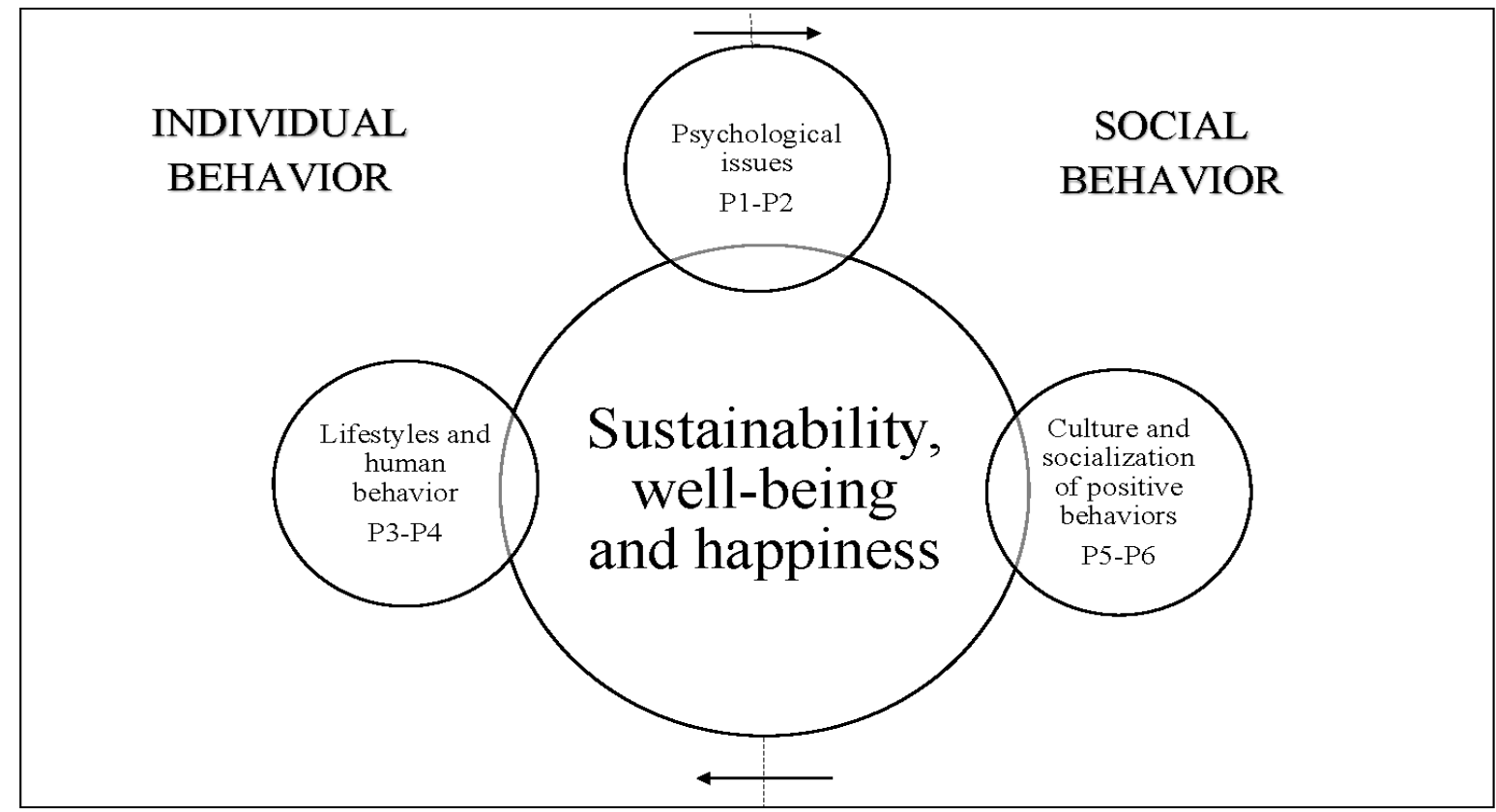

Source: Author's elaboration

The model focuses on the relation among sustainability, well-being, and happiness underlining the relevance of psychological issues, lifestyles, human behavior, and the culture and socialization of positive behaviors. Within this framework, the pivotal role of the concept of "behavior" emerges. Specifically, two spheres of behavior become important: the individual and the social. Starting from an individual perspective, people adopt a behavior grounded in a personal psychological foundation that depicts lifestyles and individual behavior. Contemporarily, this behavioral grounds of psychological features depends on what other individuals do and contribute to the socialization of a positive culture oriented to develop sustainability, well-being, and happiness. The two spheres - individual and social - create a synergetic circle in which they are continuous and in reciprocal improvement and influence.

\subsection{Implications and limitations}

Findings show several implications for academic and practitioners.

The main contribution can be summarized in the interpretive model based on the above-mentioned propositions which demonstrate that the concepts of sustainability, well-being, and happiness are related and based on: psychological issues, lifestyle and human behavior, culture, and socialization of positive behaviors. What joins these three aspects is the focus on the behavior, considered both in the individual and social spheres.

Another implication refers to the focus on the concept of sustainable happiness, which offers a fresh approach to happiness that suggests reflection on issues of sustainability, coupled with opportunities to enhance quality of life and contribute to the well-being of individuals, communities, firms, and the world.

Finally, findings show an important gap in the literature: the lack of the joint analysis of sustainability, well-being, and happiness within firms and enterprises. This underlines the need for more efforts by scholars to fill the mentioned gap.

From a managerial point of view, starting from the central role played by behavior (which clearly emerged as a significant finding), managers can take advantage of these results to achieve organizational objectives because people's behavior and commitment are more likely to be sustainable when psychological well-being is high (Robertson \&Cooper, 2009).

Robertson and Birch have found preliminary evidence of the importance of psychological well-being for sustaining employee engagement: "the highly engaged individuals with high levels of well-being are the most productive and happiest employees, while employees with low levels of well-being are more likely to leave organizations in which they operate" (2010).

They also suggest that, if organizations only focus on initiatives that target commitment and discretionary efforts, without nurturing employees' psychological well-being, then these initiatives will be limited in the impact they can achieve. 
Another key message that emerged from this study is that sustainability is defined as responsible behavior, which is a premise for a state of well-being (O'Brien, 2013). The implication here is that creating and sustaining a condition of wellness is an important way to ensure an authentic emotional and sustainable engagement. In other words, managers who manage in ways that not only encourage employees to demonstrate engagement externally by their actions but also engender emotional engagement represent a vital mechanism for creating a workforce that is sustainably engaged and productive.

The main drawback of this study is the use of a single database that, however, cover a wide range of leading journals. This limitation can be overcoming by combining other sources.

\section{Conclusion}

This paper, based on a co-word analysis and a narrative literature review of seminal articles published from 1999 to 2017 and retrieved from Scopus database, has underlined the intellectual structure of a specific topic: the joint consideration of sustainability, well-being, and happiness. The main contribution is the proposed interpretive model, based on the central role of individual and social behavior. This model suggests several new streams of research that scholars are invited to investigate. Interesting further research can be the identification of specific indexes or indicators to test the model within different settings and across time, by focusing particularly on entrepreneurship to contribute to filling the gap mentioned. Firms represent a relevant kind of organization that can effectively produce and spread positive effects from their behavior to generate a quick socialization of sustainable behavior oriented on the achievement of individual and social well-being and happiness. In this sense, scholars can promote empirical studies aimed at investigating whether firms are able to spur internal and external behaviors to generate a new culture grounded in sustainability, well-being, and happiness across all aspects of human lives.

\section{References}

Abdel-Khalek, A.M. (2005). Happiness and death distress: Two separate factors. Death Studies, 29(10), 949-958.

Alvesson, M., \& Sandberg, J. (2011). Generating research questions through problematization. Academy of Management Review, 36(2), 247-271.

Alkire, S. (2015).Well-being, happiness, and public policy. Centre for Bhutan Studies \& GNH Research: Thimphu, Bhutan.

Andersson, D., Nässén, J., Larsson, J., \&Holmberg, J. (2014). Greenhouse gas emissions and subjective well-being: An analysis of Swedish households. Ecological Economics, 102, 75-82.

Barrington-Leigh, C. (2016).Sustainability and well-being: A happy synergy. Development, 59(3-4), 292-298.

Basiago, A.D. (1999). Economic, social and environmental sustainability in development theory and urban planning practice.The Environmentalist, 19(1), 145-161.

Bechtel, R.B., \&Corral-Verdugo, V. (2010).Happiness and sustainable behavior. In V. Corral-Verdugo, C. GarciaCadena, \& M. Frias-Armenta (Eds.), Psychological approaches to sustainability (pp. 185-204). New York, NY: Nova Science Publishers.

Bekhet, A.B.,Zauszniewski, J. A., \&Nakhla, W. E. (2008). Happiness: Theoretical and empirical consideration. Nursing Forum, 43(1), 12-23.

Brown, K. W.,\&Kasser, T. (2005). Are psychological and ecological well-being compatible? The role of values, mindfulness, and lifestyle. Social Indicators Research, 74(2), 349-368.

Brülde, B. (2007). Happiness theories of the good life. Journal of Happiness Studies, 8(1), 15-49.

Brundtland, G.H. (1987). Report of the World Commission on environment and development: Our Common Future (WCED). New York: United Nations.

Buunk, B., \&Schaufeli, W. (1999). Reciprocity in interpersonal relationships: An evolutionary perspective on its importance for health and well-being. European Review of Social Psychology, (10), 259-291.

Cacioppo, J.T., Gardner, W. L., \&Berntson, G. G.(1999). The affect system has parallel and integrative processing components: Form follows function. Journal of Personality and Social Psychology, 76(5), 839-855.

Choi, J. (2016). Sustainable behavior: Study engagement and happiness among university students in South Korea. Sustainability, 8(7), 1-11.

Cloutier, S., Karner, A., Breetz, H. L., Briggs, A. D., \& Carlson, C. (2017). Measures of a sustainable commute as a predictor of happiness. Sustainability, 9(7), 1214.

Cobo, M.J., López-Herrera, A. G., Herrera, F., \&Herrera-Viedma, E. (2012a).A note on the ITS topic evolution in the period 2000-2009 at T-ITS.IEEE Transactions on Intelligent Transportation Systems, 13(1) 413-420. 
Cobo, M.J., Lòpez-Herrera, A. G., Herrera, F., \&Herrera-Viedma, E. (2012b). SciMAT: A new science mapping analysis software tool. Journal of the American Society for Information Science and Technology, 63, 16091630.

Corral-Verdugo, V., Tapia, C., García, F., Varela, C., Cuen, A., \&, Barrón, M. (2012). Validation of a scale assessing psychological restoration associated with sustainable behaviours. Psychology, 3 87-100

Dasgupta, P. (2004). Human well-being and the natural environment. Oxford: Oxford University Press. Development, $59(3-4)$.

De Young, R. (1996). Some psychological aspects of a reduced consumption lifestyle: The role of intrinsic satisfaction and competence motivation. Environment \& Behavior, 28(3), 358-409.

Di Fabio, A. (2017). The psychology of sustainability and sustainable development for well-being in organizations. Frontiers in Psychology, 8(SEP), 1534.

Diaz, S.,Fargione, J., Stuart Chapin, F., \&Tilman, D. (2006). Biodiversity loss threatens human well-being. PLoS Biology, 4(8), e277.

Ehrlich, P.R.,\& Ehrlich, A. H. (2009). The population bomb revisited. The Electronic Journal of Sustainable Development, 1(3), 63-71.

Ekins, P.,Dresner, S., \& Dahlstrom, K. (2008).The four-capital method of sustainable development evaluation. European Environment,18(2), 63-80.

Elgin, D., \&Mitchell, A. (1977). Voluntary Simplicity. Planning Review, 5(6), 13-15.

Evans, A.S. (2006). Preserving the consciousness of a nation: Promoting Gross National Happiness, in Bhutan Through Her Rich Oral Traditions. Journal of Bhutan Studies, 15, 115-138.

Fukuda, S., Murakami, M., Noda, K., \&Oki, T. (2016).How achieving the Millennium Development Goals increases subjective well-being in developing nations. Sustainability, 8, 189.

Gandelman, N.,Piani, G., \&Ferre, Z. (2012). Neighborhood Determinants of Quality of Life. Journal of Happiness Studies, 13(3), 547-564.

Gladwin, T.N.,Krause, T., \&Kennelly, J. J. (1995). Beyond eco-efficiency: Towards socially sustainable business. Sustainable Development, 3(1), 35-43.

Green, B.N., Johnson, C. D., \&Adams, A. (2006). Writing narrative literature reviews for peer-reviewed journals: secrets of the trade. Journal of Chiropractic Medicine, 5(3), 101-117.

Grinde, B. (2002). Happiness in the perspective of evolutionary psychology. Journal of Happiness Studies, 3(4), 331354.

Grinde, B. (2004). Darwinian happiness: Can the evolutionary perspective on well-being help us improve society? World Futures. The Journal of General Evolution, 60,317-329

Hacking, T., \&Guthrie, P. (2008).A framework for clarifying the meaning of triple bottom-line, integrated, and sustainability assessment. Environmental Impact Assessment Review, 28, 73-89.

Hammersley M. (2001). On "systematic" reviews of research literatures: A "narrative" response to Evans and Benefield. British Educational Research Journal, 27(5),543-554.

Helne, T., \& Hirvilammi, T. (2015). Wellbeing and sustainability: A relational approach. Sustainable Development, 23(3), 167-175.

Iwata, O. (2001). Attitudinal determinants of environmentally responsible behavior. Social Behavior and Personality, 29(2), 183-190.

Jacob, J.C., Brinkerhoff, M. B., \&Jovic, E. (2009). Personal and planetary well-being: mindfulness meditation, proenvironmental behavior and personal quality of life in a survey from the social justice and ecological sustainability movement. Social Indicators Research, 93, 275-294.

Jeyasekar, J.J.,Saravanan, P. (2012). Scientometric analysis of forensic science publications: A study based on SCOPUS database. Proceedings of the UGC-SAP National Seminar on Scientometrics and Informetrics. Annamalai Nagar, India: Annamalai University, 75-78.

Kahneman, O. (1999). Objective happiness. In Well-being: the foundations of hedonic psychology (ed. E. Diener, N. Schwarz, and 0. Kahneman), 3-27.Russell Sage Foundation, New York.

Kaiser, F. (1998). A general measure of ecological behavior. Journal of Applied Social Psychology, 28,395-442.Kasser, T. (2009). Psychological need satisfaction, personal well-being, and ecological sustainability. Ecopsychology, $1,175-180$.

Khasseh, A. A., Soheili, F., Moghaddam, H. S., \& Chelak, A. M. (2017). Intellectual structure of knowledge in iMetrics: A co-word analysis. Information Processing and Management, 53(3), 705-720

Kjell, O.N.E. (2011). Sustainable well-being: A potential synergy between sustainability and well-being research. Review of General Psychology, 15(3), 255-266.

Levett, C. (2010). Well-being and happiness - worth striving for. Australian Nursing Journal, 18(5), 48-49 
Lim, J. Y., Yoo, S.H., \&Won, D.(2016). A human-needs-based dynamic to simulate technology policy and its effects on both business success and human happiness. Sustainability, 8(12), 1225.

Lyubomirsky, S., \&Lepper, H. S.(1999). A measure of subjective happiness: preliminary reliability and construct validation. Social Indicators Research, 46(2), 137-155.

Munier, N. (2005).Introduction to sustainability - Road to a better future. Springer, Dordrecht.

Napier, J.L., \&Jost, J. T.(2008). Why are conservatives happier than liberals? Psychological Science, 19, 565-572.

Noddings, N. (2003).Happiness and education. New York: Cambridge University Press.

O'Brien, C. (2008). Sustainable Happiness: How Happiness Studies Can Contribute to a More Sustainable Future. Canadian Psycology, 49(4), 289-295.

O’Brien, C. (2012). Sustainable Happiness and Well-Being: Future Directions for Positive Psychology. Psychology, 3(12), 1196-1201.

O’Brien, C. (2013). Happiness and sustainability together at last! Sustainable happiness. Canadian Journal of Education, 36(4), 228-256.

Oskamp, S. (2000).A sustainable future for humanity? American Psychologist, 55, 496-508.

Oswald, A.J., Proto, E., \& Sgroi, D. (2014). Happiness and productivity. Discussion Paper JOLE $3{ }^{\text {rd }}$ Revision, Bonn, Germany.

Partridge, E. (2005).Social sustainability: a useful theoretical framework? Conference Paper, Australasian Political Science Association Annual Conference 2005.

Pol, E. (2002). The theoretical background of the City-Identity-Sustainability Network. Environment \& Behavior, 34, 825.

Robertson, I., \&Birch, A. J.(2010). The role of psychological well-being in employee engagement. Paper presented at British Psychological Society Occupational Psychology Conference, Brighton. January.

Robertson, I.,\&Cooper, C. L.(2009). Full engagement: the integration of employee engagement and psychological wellbeing. Leadership and Organisation Development Journal, 31(4), 324-336.

Rojas, M. (2011). The measurement of economic performance and social progress report and quality of life: moving forward. Social Indicators Research, 102(1), 169-180.

Schultz, P.W. (2001). The structure of environmental concern. Concern for self, other people, and the biosphere. Journal of Environmental Psychology, 21, 327-339.

Sen, A. (2009). Development as freedom. Oxford: Oxford University Press.

Sneddon, S.C., Howarth, R.B., \& Norgaard, R. B. (2006). Sustainable Development in a Post-Brundtland World.Ecological Economics, 57(2), 253-268.

Tapia-Fonllem, C., Corral-Verdugo, V., Fraijo-Sing, B., \&Durón-Ramos, M.F.(2013).Assessing sustainable behavior and its correlates: A measure of pro-ecological, frugal, altruistic and equitable actions. Sustainability, 5(2), 711-723.

Tashi, K. P. 2004. The role of Buddhism in achieving gross national happiness. Proceeding of the First International Seminar on GNH in Ura, K., and Galay, K. (Eds.). Gross National Happiness and Development: Proceedings of the First International Seminar on Operationalization of Gross National Happiness. Thimphu: Centre for Bhutan Studies.

Turcotte, M. (2006). Like commuting? Workers' perceptions of their daily commute. Canadian Social Trends, 28, 3541.

Veenhoven, R. (2007). Quality-of-Life Research. In Bryant, C.D. and Peck, D.L., 21st Century Sociology. A Reference Handbook. Thousand Oaks: Sage Vol. 2 54-62.

Veenhoven, R. (2008). Healthy happiness: Effects of happiness on physical health and the consequences for preventive health care. Journal of Happiness Studies, 9, 449-469.

Vlek, C.,\&Steg, L. (2007). Human behavior and environmental sustainability: Problems, driving forces, and research topics. Journal of Social Issues, 63, 1-9.

Wu, D., Xie, Y., Dai, Q., \& Li, J. (2016). A systematic overview of operations research/management science research in Mainland China: Bibliometric analysis of the period 2001-2013. Asia-Pacific Journal of Operational Research, 33(06), 1650044.

Xiao, J.J.,\&Li, H.(2011). Sustainable consumption and life satisfaction. Social Indicators Research, 104(2), 323-329. 